\title{
RISK FACTORS OF CRASHES INVOLVING MOTORCYCLES IN SRI LANKA
}

\section{N Amarasingha}

Faculty of Engineering, Sri Lanka Institute of Information Technology, Malabe, Sri Lanka

Correspondence should be addressed to niranga.a@sliit.lk

\begin{abstract}
Motorcycle is among the most popular and important modes of land transportation in tropical developing countries like Sri Lanka. Yet, research on the effect of motorcycles on traffic safety in Sri Lanka is limited.

Investigation of the risk factors and contributory causes of motorcycle crashes using data sourced from Police records was the objective of this research. Police-reported crash data in Sri Lanka contain details of crashes at all severity levels that got reported, together with their corresponding different conditions, including environment, roadway, rider, and vehicle characteristics, throughout the country. Investigating the odds-ratios, the risk factors for motorcycle crashes could be identified in developing the potential counter-measures to improve traffic safety.

In Sri Lanka, during 2009-2013, more than 200,000 of motorcycle crashes have been reported. The predominant crash conditions associated with motorcycles were driving on rural roadways, during weekdays, and riding newer motorcycles. The odds-ratios indicated that riding a motorcycle on dry surface conditions, on urban roads, and using safety helmets would be much safer.

The results of the study add new insights to the traffic safety literature in regard to improving road safety in Sri Lanka.
\end{abstract}

Keywords: Motorcycle Crashes, Injury Severity Model, Motorcycle Safety 


\section{INTRODUCTION}

According to the Global Status Report on Road Safety published in 2018, road traffic crashes, which could be prevented, was the eighth most influential cause of fatalities in the world [1]. The total number of road traffic fatalities in the world is 1.35 million per year while approximately 50 million injuries annually are reported due to traffic crashes [1]. The average road traffic fatality rate in 2018 was 18 per 100,000 population, which is comparable with that in the Eastern Mediterranean and Western Pacific countries. The fatality rates were 23.6, 29.3, and 5.1 per 100,000 population in the middle-income countries, low-income countries and in high-income countries respectively. When investigating Police-reported crashes in Sri Lanka, it was found that fatality rate in 2013 was approximately 11 per 100,000 whereas in middleincome countries that was 20.1 per 100,000 in the same year [2]. Figure 1 shows the fatal, grievous injury, and non-grievous injury trends due to traffic crashes in Sri Lanka from 2004 to 2013. Sri Lanka had an increasing trend in the total traffic injury rates during 2004 to 2012; however, the rates in 2013 were slightly lower than that of 2012.

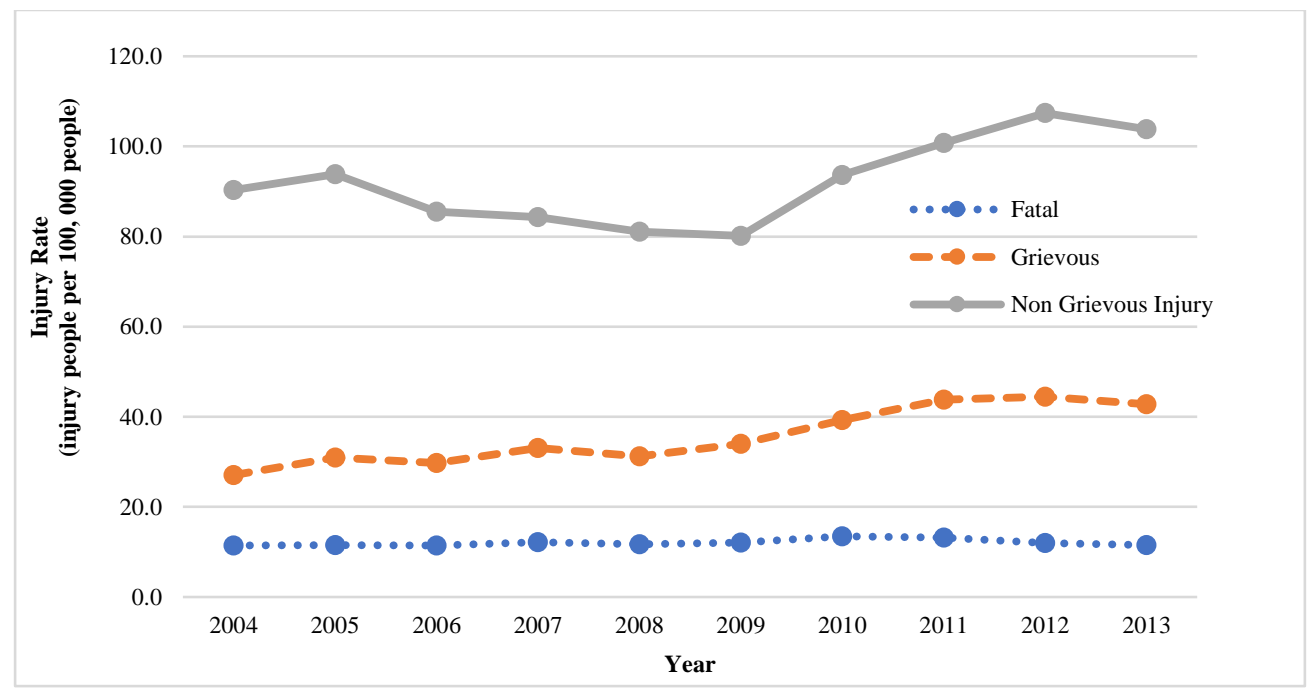

Figure 1: Traffic Injury Rate in Sri Lanka from Year 2004-2013 [2]

Middle-income countries showed no reduction in the fatality rates from 2013 to 2016 [1]. In South-East Asian countries about $43 \%$ of traffic fatalities were due to motorised two-wheelers or three-wheelers involved crashes, $16 \%$ were due to nonmotorised two-wheeler crashes, and $14 \%$ due to pedestrian crashes. Motorcycle has become an essential vehicle among the people in those countries for commuting or transporting goods because it is an economical and easy mode to be used for short distances. In South-East Asian countries, relative use and ownership of motorcycles 
or non-motorised two-wheelers are high - for example, in Thailand $86 \%$ of households own at least one motorcycle, which is comparatively higher than that in high-income countries [3].

Motorcycles in Sri Lanka usually share the lane with fast-moving vehicles such as cars, buses, and trucks. Motorcycle users are more vulnerable compared to travellers in fast-moving traffic, because motorcycles are less visible owing to their smaller size, and because they lack protection during a crash. As a result, motorcycle crashes are often reported with severe injuries caused to its users. However, even though the higher risks faced by motorised two-wheeler riders is often documented, the knowledge pertaining to the measures that should be taken to reduce or prevent this high crash risk is incomplete.

Several scientific studies have attempted to explore the factors that cause increasing crash severity associated with motorcycles, including different environmental, road, vehicle, and human factors. However, results of those studies appear inconclusive as they have yielded different priorities pertaining to those factors [4]. The conjunctural and circumstantial differences at different study areas associated with driver-, traffic-, vehicle-, road-, and environmental-related factors could possibly have been behind such mixed results. Also, the techniques used in data collection and statistical methods of analysis could also have given rise to different results. Thus, it becomes necessary to undertake further studies using country-specific data and appropriate statistical methods so that the outcomes would possibly yield a clearer and complete picture pertaining to road safety characteristics attributable to that particular country.

This study focused on investigating the risk factors and contributory causes of crashes involving motorcycles using reported data pertaining to accidents obtained from the Sri Lanka Police. It has been identified that the safety helmets were effective in reducing the injury severity in the case of motorcycle crash specially by preventing head injuries. In this study, the effect of safety helmets in reducing the injuries in the case of motorcycle crashes of Sri Lanka was also investigated.

All Sri Lankan regulations for motor vehicles are applicable to motorcycles [5]. The owners are required to register their vehicles at the Department of Motor Traffic and riders have to obtain a driving license to operate motorcycles. Every year thereafter, they are required to obtain annual revenue licenses. Motorcycle is a popular vehicle among middle-income and low-income people in Sri Lanka and mainly used to commute to work, to transport goods, as well as for recreational purposes as a family vehicle.

The distribution of registered number of vehicles in Sri Lankan during 2016 is shown in Figure 2 [6]. 


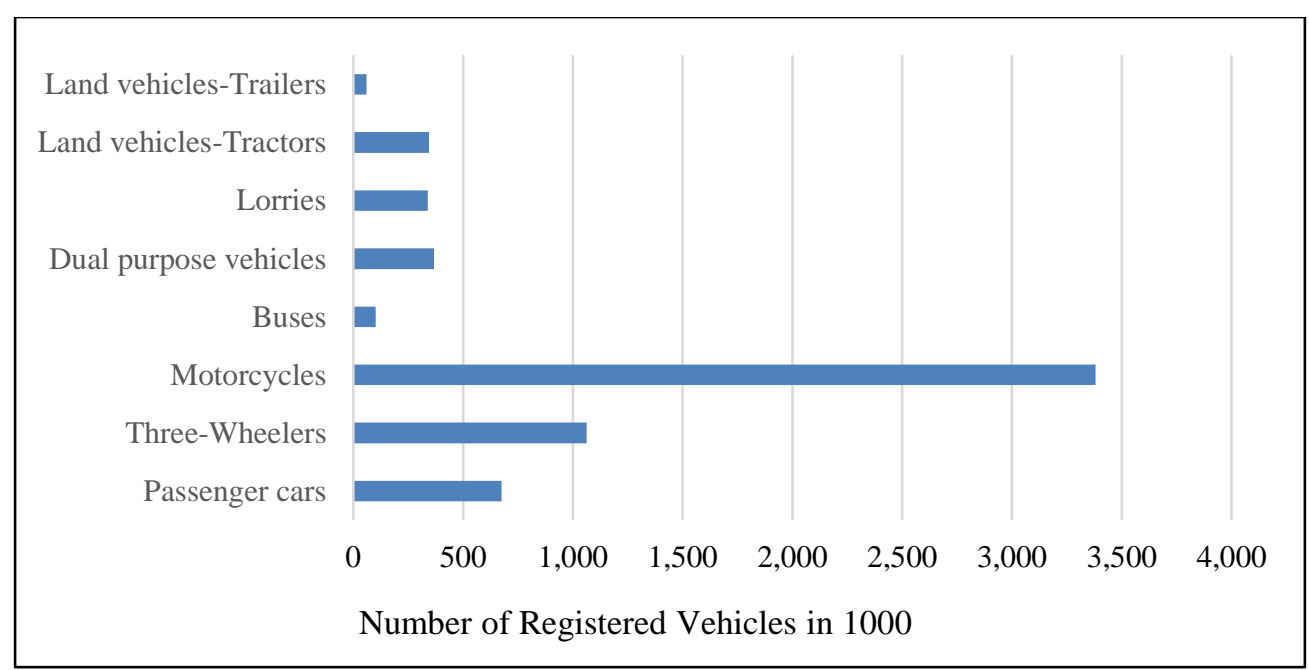

Figure 2: Type of Registered Sri Lankan Vehicle in 2016 [5]

The most common vehicle on Sri Lankan roads is the motorcycle and the number of motorcycles is three times that of the second most common vehicle, the threewheeler. For instance, in 2016, a total of 3,381,726 motorcycles was registered in Sri Lanka, which was $53.4 \%$ of the total registered vehicles in the same year, as shown in Figure 3 [6].

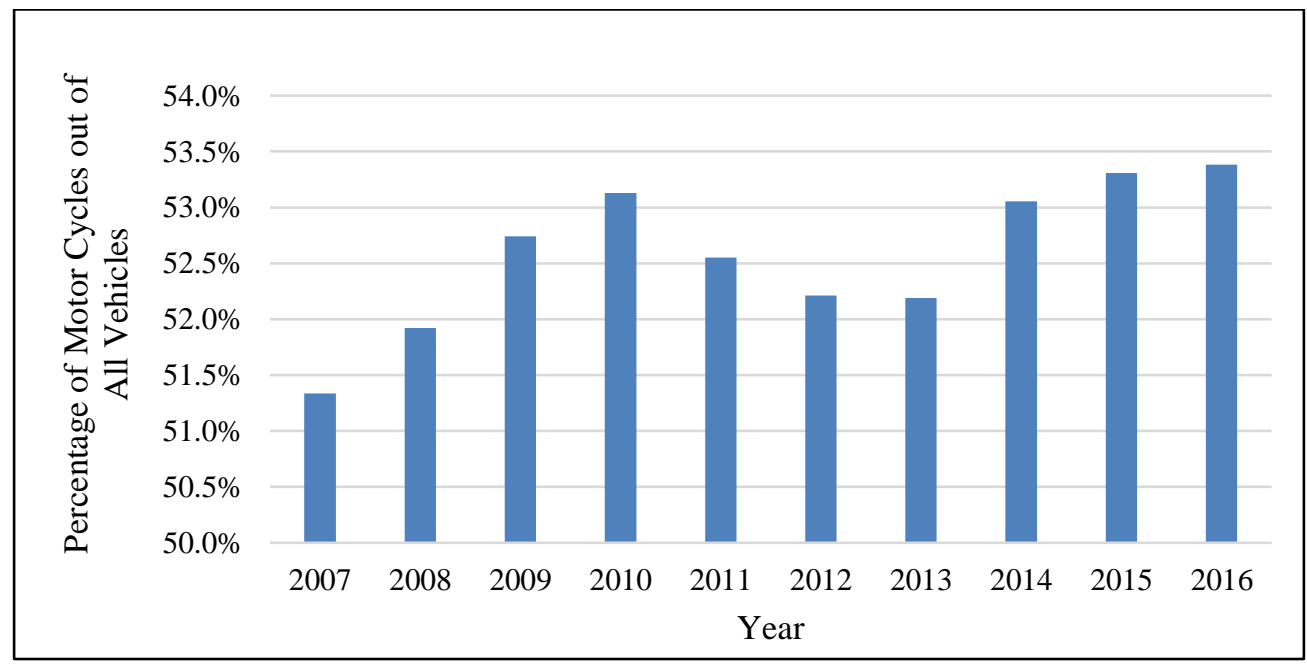

Figure 3: Percentage of Registered Motorcycles in Sri Lanka out of all Registered Vehicles [5]

The ownership and use of motorcycles and other two-wheelers in middle-income and low-income countries is usually higher than that in high-income countries. Registration of motorcycles in Sri Lanka has increased by $210 \%$ between 2007 and 
2016, resulting in a $2.8 \%$ increase in the corresponding modal share. This reflects the trend of motorcycles gaining popularity, both in ownership and ridership. The probability of motorcycle crashes increases with this increasing number of motorcycles and modal share, and therefore, much more intensive effort is needed to improve their safety on roads.

Table 1: Injury Rates and Numbers of Motorcycle Crashes in Sri Lanka during 2009-2013 [2]

\begin{tabular}{|c|c|c|c|c|c|c|c|c|}
\hline \multirow{2}{*}{ Year } & \multicolumn{2}{|c|}{ Fatal Injury } & \multicolumn{2}{|c|}{ Grievous Injury } & \multicolumn{2}{|c|}{ Non-grievous Injury } & \multicolumn{2}{c|}{ Total } \\
\cline { 2 - 9 } & No. & $\begin{array}{c}\text { Rates per } \\
\text { 1000 MC }\end{array}$ & No. & $\begin{array}{c}\text { Rates per } \\
\text { 1000 MC }\end{array}$ & No. & $\begin{array}{c}\text { Rates per } \\
\text { 1000 MC }\end{array}$ & No. & $\begin{array}{c}\text { Rates per } \\
\text { 1000 MC }\end{array}$ \\
\hline $\mathbf{2 0 0 9}$ & 4,240 & 2.24 & 10,503 & 5.54 & 21,081 & 11.12 & 35,824 & 18.89 \\
\hline $\mathbf{2 0 1 0}$ & 4,782 & 2.28 & 12,003 & 5.71 & 24,258 & 11.55 & 41,043 & 19.54 \\
\hline $\mathbf{2 0 1 1}$ & 4,665 & 1.98 & 13,474 & 5.72 & 25,159 & 10.69 & 43,298 & 18.39 \\
\hline $\mathbf{2 0 1 2}$ & 4,262 & 1.67 & 13,980 & 5.49 & 27,888 & 10.95 & 46,130 & 18.12 \\
\hline $\mathbf{2 0 1 3}$ & 4,047 & 1.53 & 13,268 & 5.02 & 25,771 & 9.75 & 43,086 & 16.31 \\
\hline
\end{tabular}

The numbers and rates of motorcycle crashes on Sri Lankan roadways between year 2009 and 2013 are shown in Table 1. These crash rates were estimated using the crash data provided by Sri Lankan Police [2]. During year 2013, around 43,086 motorcycle crashes occurred on Sri Lankan roadways, out of which 4,047 were fatal crashes [2]. The highest motorcycle crash rate and the highest number of fatal motorcycle-crashes recorded in 2010. From year 2009 to 2012, the annual number of motorcycle crashes has increased. There has been a slight decline in those injury rates of motorcycle crashes over the last three years, but safety of motorcycle riders has remained a major concern.

Before 2011, wearing safety helmet was not mandatory in Sri Lanka for some types of motorcycles with low engine capacity, such as moped motorcycles [7]. The law was revised requiring safety helmets when riding any type of motorcycles with effect from 2011. If a motorcycle is involved in a crash, wearing a safety helmet would reduce the risk of head injury. Many studies have been conducted to investigate the effects of a motorcycle helmet in preventing head injuries in case of a crash. Results pertaining to the safety of helmet use differed depending on the study type, population, situation etc. Therefore, the effectiveness of safety helmet in reducing crash injuries in the Sri Lankan context needs to be further investigated. 
Not only the number of motorcycles on Sri Lankan roads increased over the years, but also, a significant change in the types of motorcycles used has been observed. Due to these changes in motorcycle types and their use, in driver characteristics, and in evolving motorcycle crash rates, it becomes important to examine whether there would be any relationship between road-, vehicle-, rider-, and environmental-related factors that could be associated with motorcycle crashes and the corresponding safety effects of helmet use.

The present study was therefore conceived with the objective of analysing motorcycle crashes of all severity levels that occurred in Sri Lanka during the period of five-years from 2009 to 2013. It attempted to identify the injury risk factors of motorcycle crashes. Understanding the contributory causes of motorcycle crashes, and those contributing towards increasing their severity, and also the effect of safety helmets on motorcycle crashes was specifically intended. The findings of the study could be used in formulating countermeasures to reduce motorcycle crashes and their severity as well as to improve the overall safety in heterogenous mixed traffic.

\section{LITERATURE REVIEW}

Covering different countries including Sri Lanka, several studies have been done on different aspects of safety helmet use, and motorcycle safety. Numerous studies have investigated the factors affecting the occurrence and severity of motorcycle crashes. The factors that contribute to increase the occurrence or severity of motorcycle crashes were similar in many studies. Some of those similar factors identified as causing head-on crashes, run-off the road, night and weekend crashes include drunk drivers, inexperienced drivers, older drivers, speeding, and inattention [8].

Motorcycle crash data were extracted from state crash databases in New South Wales, during the 5-year period from 2004 to 2008 by Rome and Senserrick to investigate the high-risk factors for severity of motorcycle crashes [9]. Also, crash-related factors, and rider behavioural factors, and crash rates by demographics were studied. Over the 5-year study period, both numbers of motorcycle registrations and crashes increased, but a decrease was observed when considered the crash rates and fatality crash rates per 10,000 registered vehicles. Unlicensed motorcycle riders were overrepresented in fatal motorcycle crashes, and young motorcycle riders also were frequently found involved in crashes than that of other motorcycle riders. About $41 \%$ of unlicensed motorcycle riders involved in crashes did not wear safety helmets and $26 \%$ of all motorcyclists were with high blood alcohol concentration. A larger proportion of motorcycle crashes occurred on roadways having the speed limit 60 $\mathrm{km} / \mathrm{h}$ or less. The results showed that crash risk patterns could provide important details to be highlighted in driver education and intervention programs. 
In order to identify motorcyclist subgroups having high crash risk and to investigate the risk factors at work, Bjørnskau et al. [10] conducted a study in Norway, using data on motorcycle rider characteristics, their behaviour, and accident risk, collected through a questionnaire survey and also from four years of fatal motorcycle crash records in Norway during 2005 and 2008. The results showed that drivers of sport bikes, and drivers whose age was less than 19 years were the high crash risk subgroups among Norwegian motorcyclists. Excessive speed was the cause for almost all fatal crashes with sport bikes. Other high-risk factors included combinations of younger age, less experience, "unsafe" attitudes, and risky driving behaviour. The age of the rider as an important factor for occurrence and severity of motorcycle crashes was confirmed by both crash data and questionnaire data.

By developing a binary logistic regression model, Haque et al. [11] investigated the occurrence of crashes owing to faults of motorcycle riders. The dependent variable used was a binary variable which indicated whether the motorcycle rider was at-fault or not-at-fault. The independent variables considered were roadway-, environmental, motorcycle-, and rider-related factors to investigate their association on crash occurrence. Non-intersections, intersections, and expressway locations were considered in investigating motorcycle riders' faults. The results showed that these locations had different effects as contributory factors to motorcycle crashes. Motorcycle riders were found vulnerable at both intersections and expressways during night-times more than during daytimes. Further, it showed that number of motorcycle riders who were not-at-fault, but involved in crashes, increased over the years.

To investigate the factors which would increase the injury severity of motorcycle riders when they involved in crashes, multinomial logistic models were developed by Geedipally et al. [12] using Police-reported crash data from Texas, United States of America. Separate probabilistic analyses were conducted developing injury severity models to study urban and rural motorcycle crashes. According to its results, alcohol consumption, gender of the rider, lighting condition at the time of crash, and presence of horizontal and vertical curves, have emerged as significant factors which increase the severity of both urban and rural motorcycle crashes. In addition, the injury severity of rural motorcycle crashes was found further accentuated by angular crashes, single-vehicle crashes, divided highways, and older motorcycle riders.

Motorcycle crashes are frequently related to combinations of risk factors such as riding without wearing safety helmets, under the influence of alcohol, and without valid licence. Therefore, Schneider et al. [13] studied the at-fault status of motorcycle riders in associated with different combinations of crash- and rider-related factors and also the effect of these factors to other high-risk behaviours. Police-reported crash 
data in Ohio years from 2006 to 2010 were used to develop a multivariate probit model. Results revealed that the younger motorcycle riders would be more likely to be at-fault in crashes. The commonly found faults were riding without wearing safety helmets, and under the influence of alcohol. When examining other vehicle-related factors, it was found that the new motorcycle riders would be more likely to be at fault compared to rider of old motorcycles. In two-vehicle crashes, motorcycle riders tended be at fault in rear-end crashes while other vehicle drivers would be more likely to be at fault at crashes at intersections and driveways; situations which limit the distance seen.

\section{METHODOLOGY AND DATA}

Data for this study were obtained from Sri Lanka Traffic Police crash database which contains characteristics of Police-reported crashes in Sri Lanka at all severity levels from year 2009 and 2013 [2]. Not all crashes get reported to the Police [14, 15]. Some crashes, particularly those having caused property damage only, may go unreported. According to research done in Kandy district, the estimated underreporting rate was in between $33.0 \%$ and $56.3 \%$ [16]. Such under-reporting of data and inadequate quality of crash data are among main constraints when undertaking traffic safety research. The Police-reported crash data in Sri Lanka contain information related to different driver-, occupant-, environment-, vehicle-, crash-, and road-related characteristics of all vehicles involved in crashes and their contributory causes. Depending on the highest level of injury sustained by vehicle occupants, the crashes are reported in three crash severity categories: non-grievous injury, grievous injury, and fatal injury. In this study, crash severity of motorcycle accidents, as recorded in the crash database, was selected as the dependant variable to investigate the influential factors for severity of motorcycle crashes.

Data pertaining to motorcycles crashes in Sri Lanka between 2009 and 2013 were used in this study. When investigating crash data, it was observed that the number of annual crashes during this period was nearly equal. Therefore, without considering the increase or decrease of number of crashes in consecutive years, the data were aggregated for this analysis. The research was conducted using the most recent data that could be sourced, as it was impossible to obtain access to Police-reported crash database after year 2013. When multiple number of motorcycles that were involved in a single crash, information pertaining all motorcycles were considered in the analysis to perceive different vehicle-related and rider-related factors. In this study, the vehicle, namely the motorcycle, was considered the unit of analysis. There could be more than one injured occupant at a motorcycle crash as, in addition to the rider. Therefore, it might be possible to have a greater number of casualties than number of 
motorcycle crashes. The terminology adopted in this paper to define occupants of motorcycle include "riders" for motorcycle operators (drivers) only, and "motorcyclists" for both motorcycle riders and other occupants.

As the first step in analysing the data, the study calculated the frequencies and percentages of motorcycle crashes. Next, a crash severity model was developed to investigate the severity of the motorcycle crashes. The crash data contains the injury severity in three-point scale: non-grievous injury, grievous injury, and fatal injury. As the number of motorcycle crashes associated with non-grievous injuries was much higher than that resulted in fatal or grievous injuries, the latter two categories were grouped together in order to develop a better model adopting the binary logistic regression methodology. Both economic and social lost due to a fatal injury or a grievous injury very high; therefore, combining these two categories would be helpful to understand risk factors for sever injuries with compared to non-grievous injuries.

\subsection{Logistic Regression Analysis}

Crash data were used to formulate a binary logistic regression model for motorcycle crashes to investigate variables that could increase the crash severity. The coefficient of the independent variables could be used to identify whether those factors would increase the severity of crashes or not [17] [18]. The dependent variable, $y$, in the developed model was crash severity, a binary variable which explains whether crash was involved with a fatal/grievous injury or not. When severity of traffic crash is considered as the dependent variable, $y$, when the $i^{\text {th }}$ crash is severe, $y=1$, otherwise $y=0$. Assuming there are $p$ influence factors that are related to dependent variable $y$, and are denoted as $X=\left(x_{1}, x_{2}, \ldots x_{p}\right)$, the probability of a fatal crash can be derived as follows.

$$
\Pi(x)=p_{i}=\frac{e^{\beta_{0}+\beta_{1} x_{1}+\cdots+\beta p x_{p}}}{1+e^{\beta_{0}+\beta_{1} x_{1}+\cdots+\beta_{p} x_{p}}}
$$

where: $\Pi(x)$ : the probability of fatal/ grievous injury crashes under the influence of $p$ number of independent variables,

$x_{i}$ : the influencing independent variables for crash severity, and

$\beta_{i}$ : regression coefficients [19].

Considering the severity of the crash to be a dichotomous dependent variable, $x_{1}, x_{2}$, $\ldots x_{p}$ are its corresponding independent variables, logit model may be established as;

$$
\operatorname{logit}(y)=x_{i}^{\iota} \beta
$$

$$
\text { in which, } \begin{aligned}
p_{i} & =p\left(y_{i}=\frac{1}{x_{i}}\right)=e^{x_{i}^{\iota} \beta} /\left(1+e^{x_{i}^{\iota} \beta}\right), \\
x_{i} & =\left(1, x_{i 1}, \ldots x_{i p}\right)^{\iota} \text { and } \beta=\left(\beta_{0}, \beta_{1}, \ldots \beta_{p}\right)^{\iota}[20] .
\end{aligned}
$$


The model could be estimated using maximum likelihood estimator which aims at deriving values for the coefficients in such a way that maximize the joint probability of observed sample. In that respect, the dependent variable is the log of odd ratio, and the estimated coefficients cannot be directly interpreted, except the direction of the relationship; that is, whether the given factor increases or decreases the probability of occurring a fatal accident. Marginal coefficients or probability at given level of independent variables could be derived using the estimated coefficient. The coefficients of logistic regression model could be estimated using the maximum likelihood method, which is an iterative numerical analysis involving successive approximations.

Therefore, using statistical software by applying a numerical method, the best estimates of coefficients $\beta_{i}$ could be obtained. In this study, Fisher scoring method in SAS software was used for the model development.

Odds-Ratios (ORs) could be estimated through binary logistic analysis [14]. Those ORs could be used to measure the relationship between crash severity and characteristics of motorcycle crashes. OR statistic could be used in crash analyses, to compare whether the probability of an event would be similar among two groups [17, 18]. The probability of the event occurring divided by the probability of that event not occurring could be defined as the "odds" of an event as shown in Equation 3 [14].

$$
\text { Odds }=\frac{P\left(y=1 / x_{1}, x_{2}, \ldots \ldots ., x_{p}\right)}{P\left(y=0 / x_{1}, x_{2}, \ldots \ldots ., x_{p}\right)}
$$

Odds Ratio (OR) is the ratio of odds of one variable as a ratio of that of another variable, as depicted in the Equation 4.

$$
\text { odds ratio }=\frac{o d d s_{1}}{o d d s_{0}}
$$

It indicates the relative effect of one independent variable (odds 0 ) on an odds dependent variable (odds 1 ); when the value of the independent variable is increased by 1.0 unit, the effect on odds dependant variable would be indicated as an increase $(\mathrm{OR}>1.0)$ or decrease $(\mathrm{OR}<1.0)$ by the Odds Ratio.

The dependent variable used in this study was the "crash severity", a binary-variable reflecting whether the motorcycle crash was fatal/grievous or not. Univariate and multivariate analyses were two approaches used in this study, depending on the number of independent variables considered at a time. The difference between univariate analysis and multivariate analysis was that the dependent variable would be affected by only one independent variable when other independent variables were kept unchanged in the univariate analysis, while the multivariate analysis would assume the dependent variable as influenced by all different independent variables. 
The independent variables used in this analysis were road-, driver-, vehicle-, and environmental-related characteristics of motorcycle crashes.

\section{RESULTS}

In Sri Lanka, a total number of 209,381 motorcycle crashes had been reported to the Police between 2009 and 2013 which included 124,157 accidents with non-grievous injuries, 63,228 with grievous injuries, and 21,996 involving fatalities. Nearly 97 percent operators involved in these crashes were males as shown in Table 2.

Table 2: Parameter definitions of independent variables and their frequencies

\begin{tabular}{|c|c|c|c|}
\hline Characteristics & Parameter Definition & $\begin{array}{r}\text { Number of } \\
\text { crashes }\end{array}$ & $\%$ \\
\hline \multicolumn{4}{|c|}{ Driver-Related Characteristics } \\
\hline Male & If driver is male $=1$, otherwise 0 & 66,294 & 96.8 \\
\hline Young drivers & If driver is young $(<20$ years $)=1$, otherwise 0 & 8,102 & 11.8 \\
\hline Middle-aged Drivers & If driver age is $21-40$ years $=1$, otherwise 0 & 44,882 & 65.6 \\
\hline Novice driver & If driver experience is $<5$ years $=1$, otherwise 0 & 54,314 & 79.4 \\
\hline Alcohol related & If alcohol or drug related $=1$, otherwise 0 & 2,957 & 4.3 \\
\hline Valid licensed & If driver had a valid license $=1$, otherwise 0 & 39,648 & 58.8 \\
\hline Safety helmet used & If driver used helmet $=1$, otherwise 0 & 42,785 & 62.5 \\
\hline \multicolumn{4}{|c|}{ Environmental-Related Characteristics } \\
\hline Dark (No daylight) & If dark $=1$, otherwise 0 & 24,371 & 35.6 \\
\hline Clear weather & If clear weather $=1$, otherwise $=0$ & 63,580 & 92.9 \\
\hline Weekdays & If weekday $=1$, otherwise 0 & 47,878 & 70.0 \\
\hline \multicolumn{4}{|c|}{ Road-Related Characteristics } \\
\hline Urban roads & If urban area $=1$, otherwise 0 & 24,507 & 35.8 \\
\hline Intersections & If intersection related $=1$, otherwise 0 & 19,493 & 28.5 \\
\hline Dry road surface & If road surface is dry $=1$, otherwise 0 & 65,300 & 95.4 \\
\hline $\begin{array}{l}\text { Light vehicle speed } \\
\text { limit }\end{array}$ & $\begin{array}{l}\text { If light-vehicle posted speed limit }>70 \mathrm{kmph}=1 \text {, } \\
\text { otherwise } 0\end{array}$ & 31,575 & 46.1 \\
\hline \multicolumn{4}{|c|}{ Vehicle-Related Characteristics } \\
\hline Vehicle Age & If vehicle age $<5$ years $=1$, otherwise 0 & 45,979 & 67.2 \\
\hline Two Vehicle Crashes & If two vehicle crashes $=1$, otherwise 0 & 60,543 & 88.5 \\
\hline \multicolumn{4}{|l|}{ Contributory Causes } \\
\hline Speeding & If speeding $=1$, otherwise 0 & 9,053 & 13.2 \\
\hline Aggressive driving & If aggressive or negligent driving $=1$, otherwise 0 & 32,561 & 47.6 \\
\hline $\begin{array}{l}\text { Other driver } \\
\text { contributory causes }\end{array}$ & If other driver contributory cause $=1$, otherwise 0 & 3,657 & 5.3 \\
\hline Vehicle-related & If crash due to vehicle factors $=1$, otherwise 0 & 3,404 & 5.0 \\
\hline Road-related & If crash due to road factors $=1$, otherwise 0 & 2,720 & 4.0 \\
\hline
\end{tabular}


Age of the motorcycle driver appeared to be one of the factors useful for understanding the characteristics of crashes involving motorcycles. While there were some young and older riders, 65.6 percent of motorcycle riders involved in crashes were between 20 and 40 years old.

About 41.2 percent of the motorcycle crashes involved riders holding no valid licence. Riders of motorcycles involved in 37.5 percent of crashes were found not wearing safety helmets. More frequent conditions associated with motorcycle crashes appeared to be driving on rural roadways, driving during weekdays, and driving newer motorcycles.

The different characteristic factors which were considered as independent variables explaining motorcycle accidents are presented in the Table 2. Among those, several were possible to be defined as continuous or discreate variables; however, in this study, better model was obtained considering independent variables as dummy variables.

To analyse the severity of motorcycle crashes in Sri Lanka occurred during the period of study, a binary-logistic regression model was adopted. The dependent variable of the model, the "injury severity", was assigned the value of 1 for a grievous or fatal injury while the value of 0 was assigned for crashes with non-grievous injuries.

The variables deployed were checked for multi-collinearity using Pearson's correlation matrix to identify the significantly independent candidate variables. Among the independent variables, a total of two correlated pairs achieved a significance level of $\mathrm{p} \leq 0.5$, which was the cut-off criteria selected for the current analysis. One variable from each pair was discarded, so that the variable providing the strongest model, i.e. the variable with the higher-magnitude of Pearson's statistic, was retained.

The model finally retained had 21 independent variables which are depicted in the Table 3. The model diagnostics showed a Likelihood Ratio Chi-Square statistic of 68.88 with a p-value $<0.001$.

The estimated ORs corresponding to such crash characteristics from the year 2009 to the year 2013 are tabulated in the Table 4. Variables such as novice drivers, clear weather condition, day of week, vehicle age, aggressive driving, road-related contributory causes were not significant at $1 \%$ level of significance in multivariate analysis. Variables such as young drivers, day of week, vehicle age, aggressive driving, other-driver contributory factors were not significant at $1 \%$ level of significance in univariate analysis as shown in Table 4. Variables such as lightvehicle speed limit of the road, speeding, road-related contributory causes were significant in both analyses; yet, indicated different results. 
Table 3: Determinants of Severity of motorcycle crashes in Sri Lanka

\begin{tabular}{|c|c|c|c|}
\hline \multicolumn{4}{|c|}{ Dependent variable: severity of traffic crash, $y=1$ if crash is severe, otherwise $y=0$. } \\
\hline Variable & Parameter Definition & $\begin{array}{l}\text { Estimated } \\
\text { coefficient }\end{array}$ & $\begin{array}{l}\text { p- } \\
\text { value }\end{array}$ \\
\hline \multicolumn{2}{|l|}{ Intercept } & 3.651 & 0.006 \\
\hline \multicolumn{4}{|c|}{ Driver-Related Characteristics } \\
\hline Male & If driver is male $=1$, otherwise 0 & $0.727 * * *$ & 0.000 \\
\hline Young drivers & If driver is young $(<20$ years $)=1$, otherwise 0 & $-0.507 * * *$ & 0.000 \\
\hline $\begin{array}{l}\text { Middle-aged } \\
\text { Drivers }\end{array}$ & If driver age is $21-40$ years $=1$, otherwise 0 & $-0.276 * * *$ & 0.000 \\
\hline Novice driver & If driver experience is $<5$ years $=1$, otherwise 0 & 0.043 & 0.185 \\
\hline $\begin{array}{l}\text { Alcohol } \\
\text { related }\end{array}$ & If alcohol or drug related $=1$, otherwise 0 & $0.324 * * *$ & 0.000 \\
\hline Valid licensed & If driver had a valid license $=1$, otherwise 0 & $-0.711 * * *$ & 0.000 \\
\hline $\begin{array}{l}\text { Safety helmet } \\
\text { used }\end{array}$ & If driver used helmet $=1$, otherwise 0 & $-0.494 * * *$ & 0.000 \\
\hline \multicolumn{4}{|c|}{ Environmental-Related Characteristics } \\
\hline $\begin{array}{l}\text { Dark (No } \\
\text { daylight) }\end{array}$ & If dark $=1$, otherwise 0 & $0.324 * * *$ & 0.000 \\
\hline Clear weather & If clear weather $=1$, otherwise $=0$ & -0.113 & 0.562 \\
\hline Weekdays & If weekday $=1$, otherwise 0 & 0.004 & 0.455 \\
\hline \multicolumn{4}{|c|}{ Road-Related Characteristics } \\
\hline Urban roads & If urban area $=1$, otherwise 0 & $-0.311 * * *$ & 0.000 \\
\hline Intersections & If intersection related $=1$, otherwise 0 & $-0.099 * * *$ & 0.002 \\
\hline $\begin{array}{l}\text { Dry road } \\
\text { surface }\end{array}$ & If road surface is dry $=1$, otherwise 0 & $-0.219 * * *$ & 0.000 \\
\hline $\begin{array}{l}\text { Light vehicle } \\
\text { speed limit }\end{array}$ & If light-vehicle posted speed limit $>70 \mathrm{kmph}=1$, otherwise 0 & $0.510 * * *$ & 0.000 \\
\hline \multicolumn{4}{|c|}{ Vehicle-Related Characteristics } \\
\hline Vehicle Age & If vehicle age $<5$ years $=1$, otherwise 0 & -0.015 & 0.376 \\
\hline $\begin{array}{l}\text { Two Vehicle } \\
\text { Crashes }\end{array}$ & If two vehicle crashes $=1$, otherwise 0 & $-1.058 * * *$ & 0.000 \\
\hline \multicolumn{4}{|c|}{ Contributory Causes } \\
\hline Speeding & If speeding $=1$, otherwise 0 & $0.510 * * *$ & 0.000 \\
\hline $\begin{array}{l}\text { Aggressive } \\
\text { driving }\end{array}$ & If aggressive or negligent driving $=1$, otherwise 0 & 0.036 & 0.456 \\
\hline $\begin{array}{l}\text { Other driver } \\
\text { contributory } \\
\text { causes }\end{array}$ & If other driver contributory cause $=1$, otherwise 0 & $-0.208 * * *$ & 0.000 \\
\hline $\begin{array}{l}\text { Vehicle- } \\
\text { related }\end{array}$ & If crash due to vehicle factors $=1$, otherwise 0 & $0.178 * * *$ & 0.000 \\
\hline Road-related & If crash due to road factors $=1$, otherwise 0 & 0.070 & 0.567 \\
\hline
\end{tabular}

Note: $* * *$-Variable significant at $1 \%$ level of significance. 
Table 4: Odds Ratios for Motorcycle Crashes in Sri Lanka from 2009-2013

\begin{tabular}{|c|c|c|c|c|c|}
\hline \multirow{2}{*}{ Characteristics } & \multirow{2}{*}{ Parameter Definition } & \multicolumn{2}{|c|}{$\begin{array}{l}\text { Multivariate } \\
\text { Analysis }\end{array}$} & \multicolumn{2}{|c|}{ Univariate Analysis } \\
\hline & & OR & p-value & $O R$ & p-value \\
\hline \multicolumn{6}{|c|}{ Driver-Related Characteristics } \\
\hline Male $^{\#}$ & If driver is male $=1$, otherwise 0 & $2.069 * * *$ & 0.000 & $2.197 * * *$ & 0.000 \\
\hline Young drivers & $\begin{array}{l}\text { If driver is young }(<20 \text { years })=1 \text {, } \\
\text { otherwise } 0\end{array}$ & $0.602 * * *$ & 0.000 & 1.024 & 0.122 \\
\hline $\begin{array}{l}\text { Middle-aged } \\
\text { Drivers }^{\#}\end{array}$ & $\begin{array}{l}\text { If driver age is } 21-40 \text { years }=1 \text {, } \\
\text { otherwise } 0\end{array}$ & $0.759 * * *$ & 0.000 & $1.093 * * *$ & 0.000 \\
\hline Novice driver & $\begin{array}{l}\text { If driver experience is }<5 \\
\text { years }=1 \text {, otherwise } 0\end{array}$ & 1.044 & 0.185 & $0.642 * * *$ & 0.000 \\
\hline Alcohol related $^{\#}$ & $\begin{array}{l}\text { If alcohol or drug related }=1 \text {, } \\
\text { otherwise } 0\end{array}$ & $1.382 * * *$ & 0.000 & $1.576 * * *$ & 0.000 \\
\hline Valid licensed ${ }^{\#}$ & $\begin{array}{l}\text { If driver had a valid license }=1 \text {, } \\
\text { otherwise } 0\end{array}$ & $0.491 * * *$ & 0.000 & $0.448 * * *$ & 0.000 \\
\hline $\begin{array}{l}\text { Safety helmet } \\
\text { used }^{\#}\end{array}$ & $\begin{array}{l}\text { If driver used helmet }=1 \text {, } \\
\text { otherwise } 0\end{array}$ & $0.610 * * *$ & 0.000 & $0.635 * * *$ & 0.000 \\
\hline \multicolumn{6}{|c|}{ Environmental-Related Characteristics } \\
\hline $\begin{array}{l}\text { Dark (No } \\
\text { daylight) }{ }^{\#}\end{array}$ & If dark $=1$, otherwise 0 & $1.383 * * *$ & 0.000 & $1.604 * * *$ & 0.000 \\
\hline Clear weather & If clear weather $=1$, otherwise $=0$ & 0.893 & 0.562 & $0.609 * * *$ & 0.000 \\
\hline Weekdays & If weekday $=1$, otherwise 0 & 1.004 & 0.455 & 0.975 & 0.234 \\
\hline \multicolumn{6}{|c|}{ Road-Related Characteristics } \\
\hline Urban roads ${ }^{\#}$ & If urban area $=1$, otherwise 0 & $0.733 * * *$ & 0.000 & $0.633 * * *$ & 0.000 \\
\hline Intersections $^{\#}$ & $\begin{array}{l}\text { If intersection } \quad \text { related }=1, \\
\text { otherwise } 0\end{array}$ & $0.906 * * *$ & 0.002 & $0.771 * * *$ & 0.000 \\
\hline Dry road surface & $\begin{array}{l}\text { If road surface is } \text { dry }=1 \text {, } \\
\text { otherwise } 0\end{array}$ & $0.803 * * *$ & 0.000 & $0.599 * * *$ & 0.000 \\
\hline $\begin{array}{l}\text { Light vehicle } \\
\text { speed limit }\end{array}$ & $\begin{array}{l}\text { If light-vehicle posted speed } \\
\text { limit }>70 \mathrm{kmph}=1 \text {, otherwise } 0\end{array}$ & $1.665 * * *$ & 0.000 & $0.757 * * *$ & 0.000 \\
\hline \multicolumn{6}{|c|}{ Vehicle-Related Characteristics } \\
\hline Vehicle Age & $\begin{array}{l}\text { If vehicle age }<5 \text { years }=1, \\
\text { otherwise } 0\end{array}$ & 0.985 & 0.376 & 0.983 & 0.231 \\
\hline $\begin{array}{l}\text { Two Vehicle } \\
\text { Crashes }^{\#}\end{array}$ & $\begin{array}{l}\text { If two vehicle crashes }=1 \text {, } \\
\text { otherwise } 0\end{array}$ & $0.347 * * *$ & 0.000 & $0.308 * * *$ & 0.000 \\
\hline \multicolumn{6}{|l|}{ Contributory Causes } \\
\hline Speeding & If speeding $=1$, otherwise 0 & $1.665 * * *$ & 0.000 & $0.500 * * *$ & 0.000 \\
\hline Aggressive driving & $\begin{array}{l}\text { If aggressive or negligent } \\
\text { driving }=1 \text {, otherwise } 0\end{array}$ & 1.037 & 0.456 & 0.029 & 0.234 \\
\hline $\begin{array}{l}\text { Other driver } \\
\text { related causes }\end{array}$ & $\begin{array}{l}\text { If other driver contributory } \\
\text { cause }=1 \text {, otherwise } 0\end{array}$ & $0.812 * * *$ & 0.000 & 0.908 & 0.345 \\
\hline Vehicle-related & $\begin{array}{l}\text { If crash due to vehicle factors }=1 \\
\text { otherwise } 0\end{array}$ & $1.195 * * *$ & 0.000 & $0.587 * * *$ & 0.000 \\
\hline Road-related & $\begin{array}{l}\text { If crash due to road factors }=1 \text {, } \\
\text { otherwise } 0\end{array}$ & 1.073 & 0.567 & $0.649 * * *$ & 0.000 \\
\hline
\end{tabular}

Note: $* * *$ - Significant at $1 \%$ level

\#: Variable significant at $1 \%$ level of significance in both multivariant and univariate analyses. 
The variables emerged significant variables at a $1 \%$ level of significance, both in multivariate and univariate analyses were used in arriving at inferences. An OR value lesser than 1 implied the variable under consideration would lead to a lesser risk, and vice versa. Lesser risk in this regard would mean that a motorcycle would be more likely to be involved in a crash resulting in a non- grievous injury than a fatal/ grievous injury.

Accordingly, riding on roads with dry surfaces or riding by wearing safety helmets, with their ORs less than 1, were found associated with non-grievous injury crashes compared to fatal/ grievous injury crashes at $1 \%$ level of significance. The variable 'male', having the highest magnitude of Odds Ratio among variables in both multivariate and univariate analyses, showed that motorcycle-involved crashes would be more likely to be causing fatal/grievous injuries when ridden by men than by women. The Odds Ratio of alcohol-impaired riders was higher than 1 indicating its significant association with crashes causing fatal/grievous injuries. On the other hand, motorcycle riders holding valid driving license were found less likely to be involved in such accidents inflicting fatal/grievous injuries. Similarly, the use of safety helmets while travelling on motorcycles would significantly lower the risk of facing severe injuries at crashes, the corresponding OR revealed.

The Odds Ratios of environment-related variables showed motorcycle crashes would be severe when occurred in 'dark' light conditions. Motorcycle crash severity on urban roads would be milder compared that on rural roads. Also, at intersections and dry road surface conditions independently would be associated with lower injury severity risk. Two vehicle crashes showed lower odds ratio, indicating lesser association with severe injuries compared to crashes involving single vehicle or multiple vehicles. Both multivariate and univariate analyses enabled identification of factors contributing to increasing severities of crashes involving motorcycles.

Many factors combine to produce circumstances that could lead to a traffic crash; there is rarely a single cause of such an event. Aggressive/negligent driving and speeding were the most frequent rider factors associated with motorcycle crashes. It was interesting to note that when the contributory cause was one of those, the helmet use has been comparatively low. Road conditions and surrounding conditions also become relevant because the possibility of the rider having to face unexpected events when travelling cannot be excluded. Defective road surfaces or defective road signs were found the main roadway-related contributory causes of motorcycle accidents; safety helmet use was found the lowest when crashes were associated with such defective road signs or speeding. The most frequent contributing causes related to motorcycle crashes and the corresponding safety helmet usage ratios are comparatively depicted in Table 5. 
Table 5: Contributory Causes and Helmet Use Involving Motorcycle Crashes

\begin{tabular}{|c|c|c|c|}
\hline \multirow{2}{*}{ Contributory Causes } & \multirow{2}{*}{$\begin{array}{c}\text { Number of } \\
\text { Motorcycle Crashes }\end{array}$} & \multicolumn{2}{|c|}{ Safety helmet used } \\
\hline & & Frequencies & $\%$ \\
\hline \multicolumn{4}{|l|}{ Driver Factors } \\
\hline Aggressive/negligent driving & 32561 & 17445 & $54 \%$ \\
\hline Speeding & 9053 & 4783 & $53 \%$ \\
\hline Influenced by alcohol/drug & 1699 & 1028 & $61 \%$ \\
\hline Error of Judgment & 1127 & 689 & $61 \%$ \\
\hline Distracted & 157 & 95 & $61 \%$ \\
\hline Fatigue/Fall asleep & 98 & 84 & $86 \%$ \\
\hline \multicolumn{4}{|l|}{ Road Factors } \\
\hline Defective road surface & 733 & 443 & $60 \%$ \\
\hline Defective road signs & 531 & 284 & $53 \%$ \\
\hline \multicolumn{4}{|l|}{ Vehicle Factors } \\
\hline Brakes & 727 & 448 & $62 \%$ \\
\hline Tyres/wheels & 172 & 115 & $67 \%$ \\
\hline \multicolumn{4}{|l|}{ Other crash factors } \\
\hline Avoiding manoeuvre & 893 & 512 & $57 \%$ \\
\hline Hit and run & 2075 & 458 & $22 \%$ \\
\hline
\end{tabular}

Crashes due to failure in the breaks were most frequent between the two vehiclerelated causes considered. Presence of one or more of these contributory factors would not by itself cause motorcyclists facing an accident but could indicate that they are at risk.

\section{CONCLUSIONS}

This study investigated the factors associated with motorcycle crashes reported in the records of Sri Lanka Police. While riding on rural roadways, riding during weekdays, and riding newer motorcycles were found as more predominant crash conditions for motorcycle crashes in Sri Lanka. The Odds Ratios indicated that traveling on dry surface conditions, traveling on urban roads, using safety helmets would be much safer. Further, riding the motorcycles during weekends would be more prone to accidents. Rider being a male, alcohol-impaired, or travelling in dark conditions would increase severity of crashes. The results of this study could be used for developing future intervention programs aimed at reducing motorcycle crashes and reducing their severity. Incorporating these findings into existing training and education programs for both motorcyclists and drivers of other vehicles could improve awareness of the public regarding risks and help them reduce the frequency of crash occurrence. 


\section{ACKNOWLEDGEMENTS}

The author acknowledges the Sri Lanka Police for providing crash data.

\section{REFERENCES}

[1] World Health Organization (WHO). Global Status Report on Road Safety: Supporting a Decade of Action, Geneva, Switzerland, 2018.

[2] Sri Lanka Police, Accident Data, 2015.

[3] Bai N., Countries with the Highest Motorbike Usage, https://www.worldatlas. com/articles/countries-that-ride-motorbikes.html accessed on 19th July, 2021.

[4] Rifaat, S. M., R. Tay, and A. de Barros. Severity of Motorcycle Crashes in Calgary. Accident Analysis \& Prevention, Vol. 49, 2012, pp. 44-49.

[5] Amarasingha, N. (2016) Risk Factors of Motorcycle Crashes in Sri Lanka, International Conference on Research for Transport \& Logistics Industry, Colombo, Sri Lanka.

[6] Department of Motor Traffic, "Total Vehicle Population and New Registration" (2015), http://www.motortraffic.gov.lk/web/index.php?option= com_content $\&$ view $=$ article \&id=84\&Itemid=115\&lang=en, Accessed on 08th January, 2015.

[7] Amarasingha, R.P.S.P., 2015. Study of motorcycle safety helmet usage rates and injury severity, Master's Thesis, University of Moratuwa, Sri Lanka.

[8] He, J., X. Shi, Z. Xu and W. Hang. Investigation and Analysis of Motorcycle Safety in Rural China, Transportation Research Records, Journal of the Transportation Research Board, Transportation Research Board of the National Academies, 2012, pp. 97-103.

[9] Rome, L. D., and T. Senserrick. Factors Associated with Motorcycle Crashes in New South Wales, Australia, 2004 to 2008, Transportation Research Records, Journal of the Transportation Research Board, Transportation Research Board of the National Academies, 2011, pp. 54-61.

[10] Bjørnskau, T., T.O. Naevestad, and J. Akhtar. Traffic Safety among Motorcyclists in Norway: A Study of Subgroups and Risk Factors, Accident Analysis and Prevention, Vol. 49, 2012, pp.50-57. 
[11] Haque, M. M., H. C. Chin, H. Huang. Modeling Fault among Motorcyclists in Crashes, Accident Analysis and Prevention, Vol. 41, 2009, pp. 327-335.

[12] Geedipally, S. R., P.A.Turner and S. Patil. Analysis of Motorcycle Crashes in Texas with Multinominal Logit Model, Transportation Research Records, Journal of the Transportation Research Board, Transportation Research Board of the National Academies, 2011, pp. 62-69.

[13] Schneider, W. H., P. T. Savolainen, D. V. Boxel, and R. Beverley. Examination of Factors Determining Fault in Two Vehicle Motorcycle Crashes, Accident Analysis and Prevention, Vol. 45, 2012, pp. 669-676.

[14] Dharmaratne, S.D., A. U. Jayatilleke, A.C. and Jayatilleke, Road Traffic Crashes, Injury and Fatality Trends in Sri Lanka: 1938-2013. Bulletin of the World Health Organization, Vol. 93, 2015, pp.640-647.

[15] Imprialou, M. and M. Quddus. Crash Data Quality for Road Safety Research: Current State and Future Directions. Accident Analysis \& Prevention, Vol.130, 2019, pp.84-90.

[16] Periyasamy, N., C.A. Lynch, S.D. Dharmaratne, D.B. Nugegoda, and T. Østbye. Under Reporting of Road Traffic Injuries in the District of Kandy, Sri Lanka. BMJ open, Vol. 3(11), 2013, p.e003640.

[17] Amarasingha, N. and S. Dissanayake. Modeling Injury Severity of Young Drivers Using Highway Crash Data from Kansas. Journal of the transportation research forum, Vol. 52 (1), 2013.

[18] Amarasingha, N. and S. Dissanayake. Gender Differences of Young Drivers on Injury Severity Outcome of Highway Crashes. Journal of safety research, Vol. 19, 2014, pp.113-e1.19.

[19] Long, J.S. (1997), Regression Models for Categorical and Limited Dependent Variables, Thousand Oaks, CA: Sage.

[20] Xi, J.F., H.Z. Liu, W. Cheng, Z.H. Zhao, and T. Q. Ding., The Model of Severity Prediction of Traffic Crash on the Curve. Mathematical Problems in Engineering, 2014. 